\title{
COMBINING CHARGE DENSITY ANALYSIS WITH MACHINE LEARNING TOOLS TO INVESTIGATE CRUZAIN INHIBITION MECHANISM
}

Adriano M. Luchi ${ }^{\S}$, Roxana N. Villafane ${ }^{\S}$, J. Leonardo Gómez Chávez ${ }^{\S}$, M. Lucrecia Bogado $^{\S}$, Emilio L. Angelina ${ }^{*}$, Nelida M. Peruchena ${ }^{* \S}$

$\S$ Lab. Estructura Molecular y Propiedades, IQUIBA-NEA, Universidad Nacional del Nordeste, CONICET, FACENA, Av. Libertad 5470, Corrientes 3400, Argentina.

*E-mail: Emilio L. Angelina: emilioluisangelina@ hotmail.com, Nelida M. Peruchena: arabeshai@yahoo.com.ar 


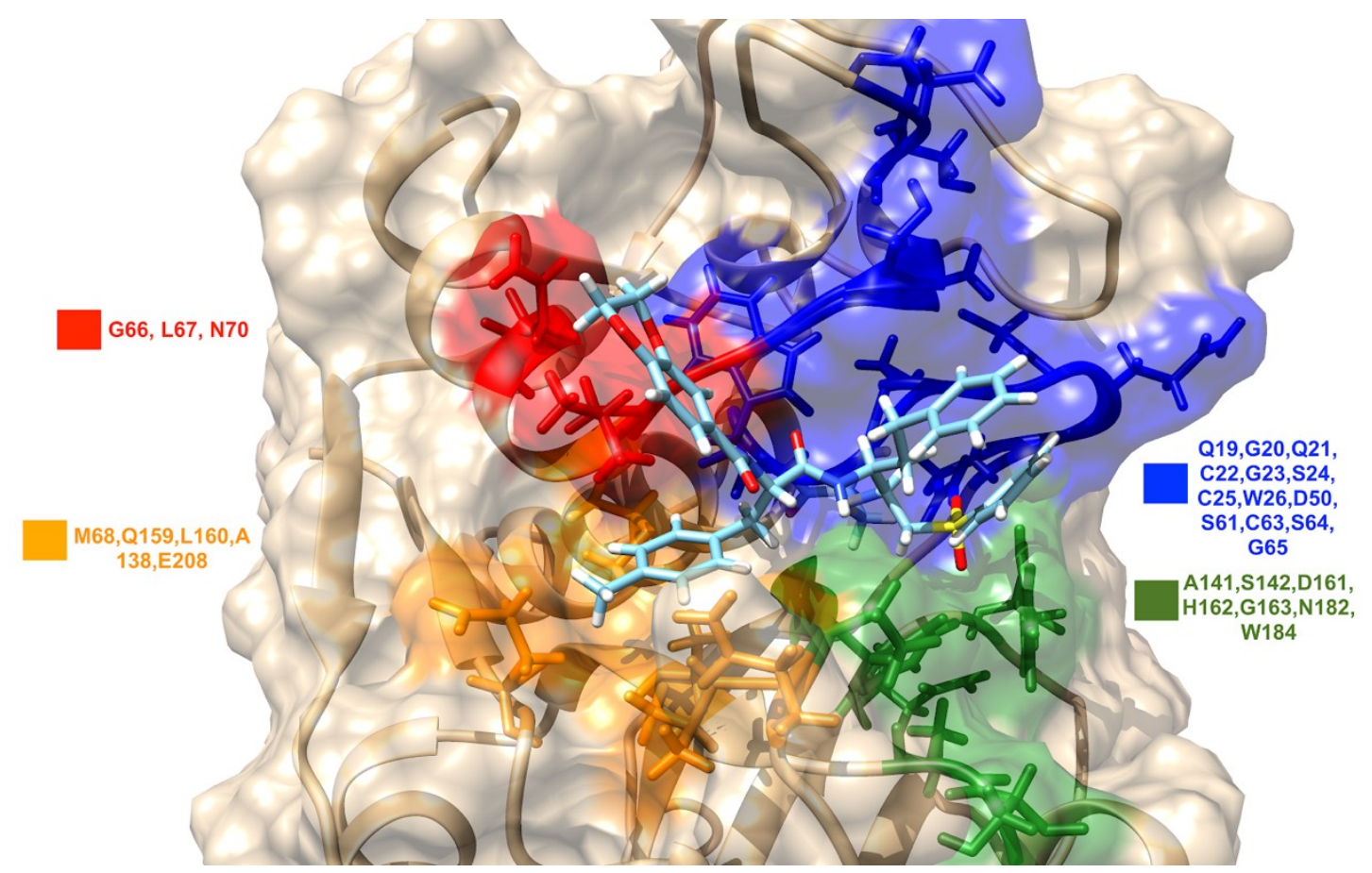

Figure S1. Cruzain surface with peptide-like vinylsulfone inhibitor bound the enzyme binding cleft. Residues that conform sub-pockets S1, S1', S2 and S3 are depicted in blue, green, orange and red, respectively. 
Table S1. Local charge density values ( $\rho$, in atomic units) corresponding to interactions discussed in main text. Interaction numbers match those from Figures 3, 5, 6 and 7 in main text.

\begin{tabular}{|c|c|c|c|c|c|c|c|c|c|c|c|c|c|c|c|c|c|c|}
\hline Complex & \multicolumn{17}{|c|}{ Interactions values $\rho(u . a)$} & 19 \\
\hline 9d-Cz & 0.0248 & 0.0218 & 0.0069 & 0.0313 & 0.0063 & 0.0198 & 0.01783 & 0.0128 & 0.0048 & 0.0296 & 0.0000 & 0.0028 & 0.0060 & 0.0398 & 0.0101 & 0.0000 & 0.0160 & 0.0080 \\
\hline 7d-Cz & 0.0325 & 0.0000 & 0.0089 & 0.0082 & 0.0283 & 0.0233 & 0.04068 & 0.0186 & 0.0065 & 0.0350 & 0.0038 & 0.0000 & 0.0087 & 0.0068 & 0.0059 & 0.0041 & 0.0069 & 0.0096 \\
\hline $6 b-C z$ & 0.0345 & 0.0217 & 0.0155 & 0.0171 & 0.0141 & 0.0273 & 0.03734 & 0.0193 & 0.0031 & 0.0307 & 0.0000 & 0.0000 & 0.0000 & 0.0272 & 0.0040 & 0.0000 & 0.0029 & 0.0057 \\
\hline 7b-Cz & 0.0000 & 0.0000 & 0.0029 & 0.0229 & 0.0221 & 0.0161 & 0.02233 & 0.0000 & 0.0000 & 0.0375 & 0.0137 & 0.0000 & 0.0205 & 0.0387 & 0.0094 & 0.0000 & 0.0116 & 0.0026 \\
\hline 7a-Cz & 0.0303 & 0.0202 & 0.0000 & 0.0336 & 0.0043 & 0.0149 & 0.01761 & 0.0117 & 0.0070 & 0.0372 & 0.0037 & 0.0047 & 0.0206 & 0.0264 & 0.0056 & 0.0000 & 0.0029 & 0.0127 \\
\hline $8 c-C z$ & 0.0242 & 0.0000 & 0.0000 & 0.0330 & 0.0115 & 0.0274 & 0.04080 & 0.0087 & 0.0085 & 0.0000 & 0.0000 & 0.0072 & 0.0201 & 0.0257 & 0.0077 & 0.0000 & 0.0031 & 0.0000 \\
\hline $8 b-C z$ & 0.0308 & 0.0339 & 0.0000 & 0.0317 & 0.0105 & 0.0168 & 0.01944 & 0.0114 & 0.0023 & 0.0123 & 0.0046 & 0.0077 & 0.0238 & 0.0090 & 0.0038 & 0.0088 & 0.0062 & 0.0079 \\
\hline $6 d-C z$ & 0.0026 & 0.0000 & 0.0004 & 0.0298 & 0.0116 & 0.0171 & 0.01648 & 0.0029 & 0.0000 & 0.0254 & 0.0046 & 0.0053 & 0.0257 & 0.0163 & 0.0040 & 0.0083 & 0.0141 & 0.0000 \\
\hline $6 a-C z$ & 0.0000 & 0.0000 & 0.0000 & 0.0265 & 0.0047 & 0.0178 & 0.03103 & 0.0045 & 0.0000 & 0.0171 & 0.0037 & 0.0065 & 0.0000 & 0.0296 & 0.0051 & 0.0000 & 0.0007 & 0.0052 \\
\hline 8d-Cz & 0.0000 & 0.0128 & 0.0000 & 0.0278 & 0.0000 & 0.0310 & 0.01675 & 0.0011 & 0.0045 & 0.0000 & 0.0000 & 0.0299 & 0.0075 & 0.0193 & 0.0071 & 0.0056 & 0.0071 & 0.0111 \\
\hline $4 b-C z$ & 0.0238 & 0.0559 & 0.0000 & 0.0378 & 0.0166 & 0.0225 & 0.02303 & 0.0084 & 0.0000 & 0.0000 & 0.0000 & 0.0066 & 0.0097 & 0.0210 & 0.0026 & 0.0033 & 0.0052 & 0.0042 \\
\hline $4 e-C z$ & 0.0264 & 0.0368 & 0.0000 & 0.0236 & 0.0057 & 0.0281 & 0.02357 & 0.0064 & 0.0141 & 0.0000 & 0.0061 & 0.0000 & 0.0124 & 0.0310 & 0.0000 & 0.0000 & 0.0000 & 0.0000 \\
\hline
\end{tabular}

